\title{
Too Much Free Time: Coos County Youth Who Are Least Involved in Out-of-School Activities Are Most Likely to Use Drugs and Alcohol
}

ER IN HILEY SHARP

$\mathrm{H}$ alf of teens' free time is spent out of school. ${ }^{1}$ How youth spend their free time has implications for their development. Structured, constructive, and personally meaningful activities can provide a rich context for youth to explore their identities, develop plans for the future, demonstrate motivation and initiative, and learn instrumental skills. ${ }^{2}$ In contrast, unengaged, bored, and uninvolved youth are at higher risk for negative outcomes, such as delinquency, substance use, and school dropout. ${ }^{3}$ Much of the research on out-of-school time and youth development has focused on youth in urban or suburban settings. Fewer have studied rural youth, particularly those living in communities facing economic hardship. These youth may spend even more time unoccupied than others. ${ }^{4}$ This fact sheet reports on the links between out-of-school activity involvement and cigarette and tobacco, alcohol, and marijuana use among eleventh graders in rural Coos County, New Hampshire.

\section{Key Findings}

- The majority of eleventh graders in Coos County do not use cigarettes, tobacco, or marijuana; however, more than 50 percent report drinking alcohol at least once in the previous six months.

- Youth who are the most involved in out-of-school activities report the least amount of substance use.

- Approximately one-third of Coos County eleventh graders report little involvement in out-of-school activities. Too much free time could be putting them at risk for substance use.

\section{Data}

This analysis is based on data from the Carsey Institute's Coos Youth Study. Coos County, New Hampshire, is a rural county facing increased poverty and unemployment from the loss of manufacturing jobs. These economic conditions have raised concerns about the long-term opportunities for youth. Survey data were collected from 339 Coos County eleventh graders (51 percent female) in 2008. Participants represented about 78 percent of the total eleventh-grade public school population in the county.

\section{Least-Involved Youth More Likely to Use Substances}

The majority of eleventh-grade youth in Coos County did not use cigarettes and tobacco or marijuana in the six months prior to completing the survey (see Table 1). However, more than 50 percent reported drinking alcohol at least once in the prior six months. These results are similar to those reported for New Hampshire eleventh graders more broadly in the 2007 Youth Risk Behavior Survey. ${ }^{5}$ However, Coos County Youth reported greater alcohol use compared with New Hampshire eleventh graders as a whole.

Students were asked whether they participated in any of sixteen different free-time activities in the past twelve months. ${ }^{6}$ The responses revealed three levels of involvement: low (defined as fewer than three activities), medium (defined as between three to six activities); and high (defined as more than seven activities). Eleventh-grade youth were split fairly evenly across these three activity groups (see Figure 1). 
TABLE 1: COOS COUNTY YOUTH REPORTING SUBSTANCE USE IN PRIOR SIX MONTHS

Tobacco/Cigarette Use Alcohol
Use Marijuana Use
Eleventh graders

\section{Never used}

Used at least once

One to two times

Three to five times

More than five times

\begin{tabular}{|c|c|c|}
\hline $74 \%$ & $47 \%$ & $77 \%$ \\
$26 \%$ & $53 \%$ & $23 \%$ \\
$4 \%$ & $21 \%$ & $10 \%$ \\
$4 \%$ & $12 \%$ & $3 \%$ \\
$18 \%$ & $20 \%$ & $10 \%$ \\
\hline
\end{tabular}

Figure 1. DegreE OF OUT-OF-SCHOOL ACTIVITY INVOLVEMENT AMONG CoOs COUNTY ELEVENTH-GRADE YOUTH

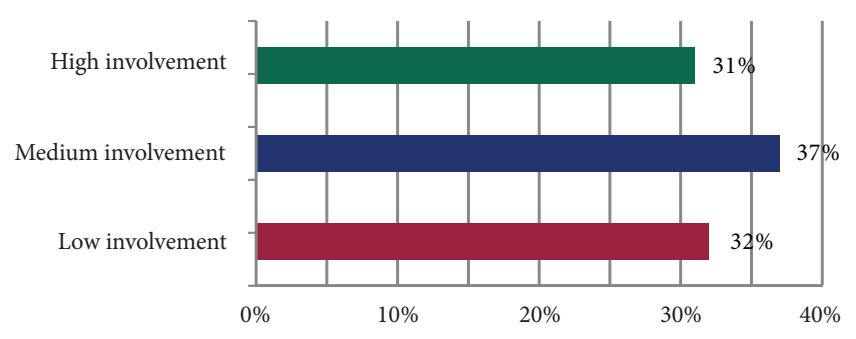

We compared the likelihood of substance use by level of activity involvement (see Figure 2) and found significant differences. For cigarettes and tobacco, alcohol, and marijuana, youth who were the least involved in out-of-school activities reported significantly more use of these substances than those who were more involved in activities.

\section{Implications}

Because of data limitations, we cannot claim that lack of activity involvement causes higher substance use. Other factors, such as family status, mental health, or success in school, could contribute to the differences we see. We also cannot determine the direction of these effects. It may be that the youth who are drawn to more activities are also the same youth who are less inclined to use substances. Fleshing out these issues of cause and effect with more rigorous data could help better target scarce program funding, particularly in rural areas. That said, an association between activity involvement and substance use is clear.
Youth who are highly involved in out-of-school activities are also the least likely to smoke cigarettes or use tobacco, drink alcohol, and use marijuana. This suggests that policies and programs that bolster out-of-school activities may also reduce substance use behaviors. About one-third of Coos County eleventh graders reported limited involvement in activities. Youth who are not engaged in activities are not only at an increased risk for negative outcomes, like substance use, but they may also miss out on opportunities for positive development. Providing a wide range of activities, reducing barriers to participation, and communicating the value of activities to officials, families, and community members can help to expand the positive activities for youth in rural communities with fewer resources, like those in Coos County.

Figure 2: Substance USE IN PAST SIX MONTHS By LEVEL OF OUT-OF-SCHOOL ACTIVITY INVOLVEMENT

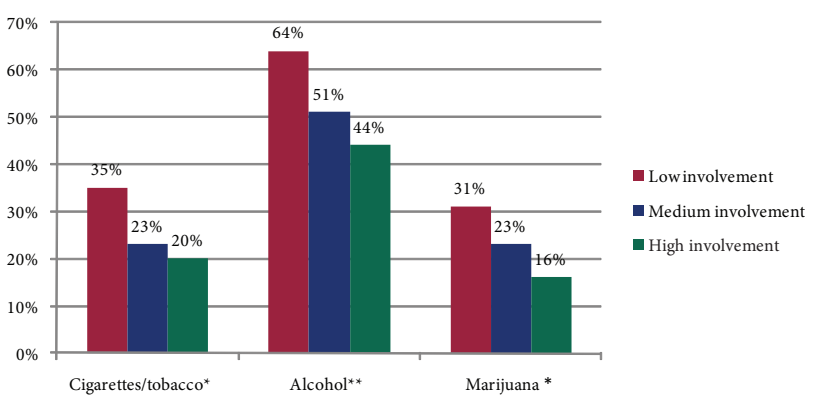

Note: Differences significant at ${ }^{*} \mathrm{p}<.05,{ }^{* *} \mathrm{p}<.01$. Sample is of eleventh graders in Coos County. 


\section{Endnotes}

1. R. Larson and S. Seepersad, "Adolescents' leisure time in the United States: Partying, sports, and the American experiment," in Examining adolescent leisure time across cultures: Developmental opportunities and risks: New Directions in Child and Adolescent Development, no. 99, eds. S. Verma and R. Larson (San Francisco: Jossey-Bass, 2003), 53-64.

2. J. D. Coatsworth et al., "Self-Defining Activities, Expressive Identity, and Adolescent Wellness," Applied Developmental Science, 10 (2006): 157-170; D. M. Hansen, R. W. Larson, and J. B. Dworkin, "What Adolescents Learn in Organized Youth Activities: A Survey of Self-Reported Developmental Experiences," Journal of Research on Adolescence, 13 (2003): 25-55; J. P. Hunter and M. Csikszentmihalyi, The Positive Psychology of Interested Adolescents," Journal of Youth \& Adolescence, 32 (2003): 27-35.

3. D. W. Osgood, A. L. Anderson, and J. N. Shaffer, "Unstructured Leisure in the After-School Hours," in Organized Activities as Contexts of Development: Extracurricular Activities, After-School and Community Programs, eds. J. L. Mahoney, R. W. Larson, and J. S. Eccles, (Mahmah, NJ: Erlbaum, 2005), 45-64; E. H. Sharp et al., "Predicting Substance Use Behavior Among South African Adolescents: The Role of Free Time Experiences" (manuscript submitted for publication, 2009).

4. R. Larson and S. Verma, "How children and adolescents spend time across the world: Work, play, and developmental opportunities," Psychological Bulletin, 125 (1999): 701-736; Casey, Ripke, and Huston, "Activity participation and the well-being of children and adolescents in the context of welfare reform," in After-School Activities: Contexts of Development, eds. J. L. Mahoney, J. S. Eccles, and R. W. Larson (Mahmah, NJ: Erlbaum, 2005). 65-84.

5. Youth Risk Behavior Survey 2007 reported 28 percent of eleventh-grade youth in New Hampshire used tobacco or cigarettes, 37 percent drank alcohol, and 34 percent smoked marijuana in the thirty days prior to the survey. http://www.ed.state.nh.us/education/doe/organization/ instruction/HealthHIVAIDS/youthrisk.htm

6. Activity choices were (1) sports; (2) student government; (3) band, choir, or music lessons; (4) drama, theater, and dance; (5) art; (6) academic club; (7) community service club; (8) 4-H or scouts; (9) volunteer work; (10) church group; (11) honor society; (12) school yearbook or newspaper; (13) hobby club; (14) community events; (15) outdoor activities; and (16) community center events.

\section{About the Author}

Erin Hiley Sharp is a Carsey Institute faculty fellow and assistant professor of family studies at the University of New Hampshire (erin.sharp@unh.edu). 


\section{THE CARSEY INSTITUTE COOS YOUTH}

\section{STUDY}

The Carsey Institute is conducting a panel study of Coos County youth that will provide data about the attitudes and experiences of the county's youth as they approach young adulthood and face the decision to remain in their community, seek opportunities elsewhere, or leave for an education and then return. By following the entire populations of two age groups over a ten-year period, we will help North Country leaders gain a better understanding of young people's decision making.

\section{RESEARCH TEAM}

Cesar Rebellon is a faculty fellow at the Carsey Institute and an associate professor in the Department of Sociology at the University of New Hampshire. His primary research interests focus on family and peer correlates of juvenile crime and delinquency, with a particular emphasis on the manner in which delinquency may yield reinforcing social rewards among adolescents.

ERIN Hiley Sharp is a Carsey Institute faculty fellow and assistant professor in the Department of Family Studies at the University of New Hampshire. Her research interests include activity involvement as a context for adolescent development; parental, family, and broader contextual influences on adolescent development; and prevention research and theory from a positive youth development perspective.

Nena Stracuzzi is an assistant research professor at the Carsey Institute. Her research focuses on vulnerable youth and families.

Corinna Jenkins Tucker is a faculty fellow at the Carsey Institute and an associate professor in the Department of Family Studies at the University of New Hampshire. Her primary research interests focus on adolescents' family relationships.

Heather Turner is a senior fellow at the Carsey Institute and a professor in the Department of Sociology at the University of New Hampshire. Her research concentrates on social stress processes and mental health.

Karen VAn Gundy is a faculty fellow at the Carsey Institute and an associate professor in the Department of Sociology at the University of New Hampshire. Her work investigates the mechanisms by which life circumstances and social statuses influence variations in health, emotional, and behavioral outcomes.

\section{A UNIVERSITY of NEW HAMPSHIRE}

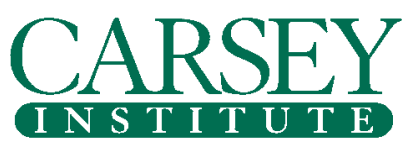

Building knowledge for families and communities

The Carsey Institute conducts policy research on vulnerable children, youth, and families and on sustainable community development. We give policy makers and practitioners timely, independent resources to effect change in their communities.

Carsey Institute Reports on Tracking Change in the North Country are supported by the Neil and Louise Tillotson Fund at the New Hampshire Charitable Foundation and the Carsey Institute endowment.

Huddleston Hall

73 Main Street

Durham, NH 03824

(603) 862-2821

www.carseyinstitute.unh.edu 